\title{
Calcineurin Activation by Prion Protein Induces Neurotoxicity via Mitochondrial Reactive Oxygen Species
}

\author{
Ji-Hong Moon, Jeong-Min Hong, and Sang-Youel Park (iD) \\ Biosafety Research Institute, College of Veterinary Medicine, Jeonbuk National University, Iksan, Jeonbuk 54596, Republic of Korea \\ Correspondence should be addressed to Sang-Youel Park; sypark@chonbuk.ac.kr
}

Received 28 January 2021; Revised 1 July 2021; Accepted 14 July 2021; Published 6 August 2021

Academic Editor: Fabrizio Biundo

Copyright () 2021 Ji-Hong Moon et al. This is an open access article distributed under the Creative Commons Attribution License, which permits unrestricted use, distribution, and reproduction in any medium, provided the original work is properly cited.

\begin{abstract}
Prion diseases are caused by PrPsc accumulation in the brain, which triggers dysfunctional mitochondrial injury and reactive oxygen species (ROS) generation in neurons. Recent studies on prion diseases suggest that endoplasmic reticulum (ER) stress induced by misfolding proteins such as misfolded prion protein results in activation of calcineurin. Calcineurin is a calciumrelated protein phosphatase of type $2 \mathrm{~B}$ that exists in copious quantities in the brain and acts as a critical nodal component in the control of cellular functions. To investigate the relationship between calcineurin and intracellular ROS, we assessed the alteration of $\mathrm{CaN}$ and ROS induced by prion peptide ( $\mathrm{PrP}$ ) 106-126. Human prion peptide increased mitochondrial ROS by activating calcineurin, and the inhibition of calcineurin activity protected mitochondrial function and neuronal apoptosis in neuronal cells. These results suggest that calcineurin plays a pivotal role in neuronal apoptosis by mediating mitochondrial injury and ROS in prion diseases.
\end{abstract}

\section{Introduction}

Prion diseases are fatal neurodegenerative conditions that cause protein accumulation in the brain. This accumulation is a key pathogenic mechanism of various neurodegenerative diseases, including Parkinson's disease and Alzheimer's disease $[1,2]$. In these diseases, the misfolded prion protein (PrPsc) is incorporated into the fibrillary beta-sheet-rich structures, known as amyloid plaques, that have been associated with numerous protein misfolding disorders [3]. Although there is literature that confirms that PrPsc strain induces neuronal apoptosis in the brain [4-6], the molecular mechanisms and signaling cascades that result in neuronal apoptosis remain unclear [7-9].

The synthetic human prion peptide ( $\mathrm{PrP}$ ) 106-126 originates in PrP molecules found in numerous species, preserves features of the physiological and pathogenic abilities of PrPsc, and can trigger neuronal apoptosis [10-12]. Amino acids 106-126 of the PrP sequence could replicate biological features of PrPsc in vitro, such as amyloidogenesis, and its neurotoxic as well as its gliotrophic effects [13-15]. Recent studies have used neurotoxic PrP peptides such as PrP 106-
126 to test the neuroprotective effect of autophagy-inducing agents [16-18].

Accumulated evidence suggests that cellular damage, such as oxidative stress caused by free radicals and various proteins, is dynamically implicated in the cellular apoptosis associated with several neurodegenerative diseases [19-23]. There is also evidence that prion-mediated neuronal cell death is related to oxidative stress [24-26]. Mitochondria play an essential role in regulating apoptosis and the production of reactive oxygen species in many neurodegenerative disorders, including prion diseases [27-29]. In in vitro models, endoplasmic reticulum (ER) stress resulting from the accumulation of misfolded prion proteins is associated with mitochondrial dysfunction and ROS production [30-32]. Over the past decade, numerous studies have used mitochondrion-targeted probe MitoSOX for mitochondrial ROS detection [33, 34]. Dichlorodihydrofluorescein diacetate (DCFH-DA) is typically used for detecting intracellular ROS [35]. To determine the role of cellular ROS and mitochondrial ROS in prion-mediated neuronal apoptosis, we performed experiments to detect cellular ROS and mitochondrial ROS. 


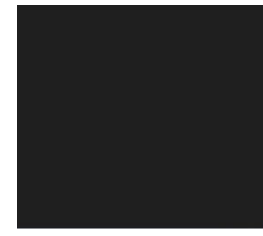

$\mathrm{N}$-con

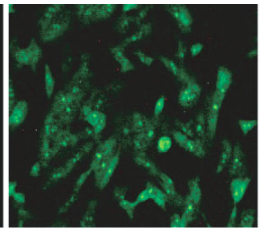

Con

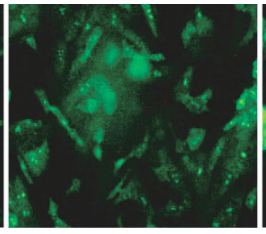

PrP

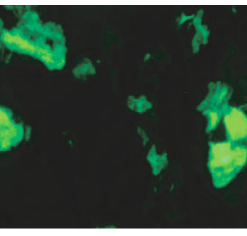

$\mathrm{A} \beta$

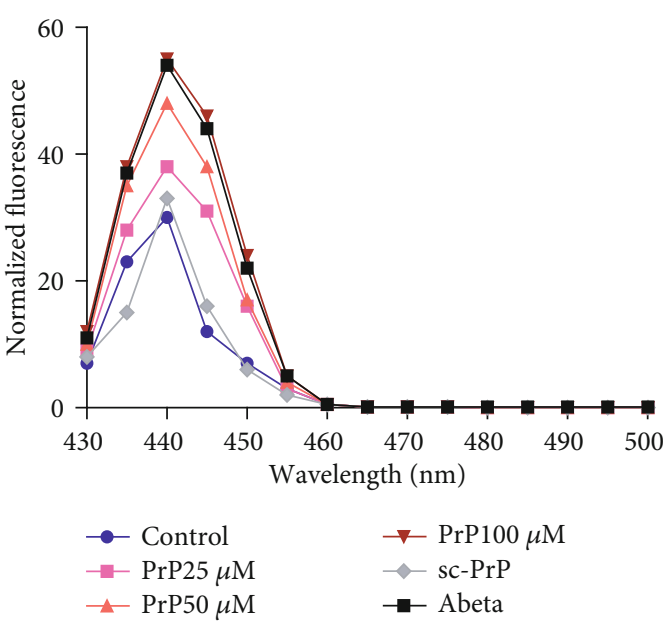

(b)

Figure 1: Prion peptide 106-126 aggregation status. (a) Neuroblastoma cells (SK-N-SH) were pretreated with $20 \mu \mathrm{M}$ ThT for 30 min and then exposed to 25, 50, and $100 \mu \mathrm{M} \operatorname{PrP} 106-126,100 \mu \mathrm{M}$ sc-PrP, or $100 \mu \mathrm{M}$ amyloid $\beta$ for $6 \mathrm{~h}$. (b) Fluorescence was evaluated by spectrum analysis and fluorescence microscopy.

Impaired calcium signaling caused by the accumulation of a misfolded prion protein triggers crosstalk between the endoplasmic reticulum and the mitochondria as a means of counteracting stress [36-38]. Our previous studies suggested that $\operatorname{PrP} 106-126$ increases intracellular calcium levels and calcineurin $(\mathrm{CaN})$ activity in neurons [39, 40]. Other researchers have shown that increased calcium levels are associated with the mitochondrial apoptotic pathway in neurodegenerative diseases that involve prions [31, 41]. When mitochondrial depolarization occurs with a sustained cytosolic rise in $\mathrm{Ca}^{2+}$, the cytosolic phosphatase activity of the serine/threonine phosphatase $\mathrm{CaN}$ is activated [42]. Activated $\mathrm{CaN}$ dephosphorylates cytoplasmic NFAT, which exposes its nuclear localization sequence and leads to rapid nuclear import [43]. CaN is a calcium-mediated type $2 \mathrm{~B}$ protein phosphatase and a crucial nodal factor in controlling cellular functions [44]. CaN is highly abundant in the brain and has been implicated in the regulation of synaptic plasticity, memory, and neuronal death [45]. The relationship between prion-mediated ROS and CaN activation has, until now, not been described. In this study, we investigated what kind of ROS is generated by a prion peptide and the relationship between $\mathrm{CaN}$ and intracellular ROS in prion in vitro models.

\section{Materials and Methods}

2.1. Cell Culture. The human neuroblastoma cell line SK-N$\mathrm{SH}$ was obtained from the American Type Culture Collection (ATCC, Rockville, MD, USA). The cell culturing method has been described previously in detail [39]. The cells were cultured in Minimum Essential Medium (HyClone Laboratories, Logan, UT, USA) containing 10\% FBS (Gibco, Grand Island, NY, USA) and gentamycin $(0.1 \mathrm{mg} / \mathrm{mL})$ in a humidified incubator at $37^{\circ} \mathrm{C}$ with $5 \% \mathrm{CO}_{2}$.

2.2. Chemical and $\operatorname{Pr} P$ (106-126) Treatment. Synthetic prion peptides PrP (106-126) (sequence, Lys-Thr-Asn-Met-LysHis-Met-Ala-Gly-Ala-Ala-Ala-Ala-Gly-Ala-Val-Val-Gly-Gly-
Leu-Gly) and scrambled $\operatorname{PrP}(106-126)$ (sequence, AsnGly-Ala-Lys-Ala-Leu-Met-Gly-Gly-His-Gly-Ala-Thr-LysVal-Met-Val-Gly-Ala-Ala-Ala) were synthesized by Peptron (Seoul, Korea) [20]. The PrP peptides were dissolved in sterile dimethyl sulfoxide (DMSO) at a concentration of $10 \mathrm{mM}$ (stock) and stored at $-20^{\circ} \mathrm{C}$.

The stock solution of FK506 (10 mM; F4679, SigmaAldrich, St. Louis, MO, USA) was dissolved in DMSO. The stock solution of $\mathrm{N}$-acetyl-L-cysteine (NAC, $1 \mathrm{M}$; A7250, Sigma-Aldrich), diethyldithiocarbamate (DDC, $100 \mathrm{mM}$; Sigma-Aldrich), and 3-amino-1,2,4-triazole (AT, $500 \mathrm{mM}$; Sigma-Aldrich) was dissolved in distilled water.

2.3. Thioflavin-T Binding Assay. Cells in the logarithmic phase were collected and cultured in 6 -well plates at $3 \times 10^{5}$ cells/well. Binding of ThT to PrP 106-126 and amyloid $\beta$ fibrils was assayed by adding $20 \mu \mathrm{M}$ ThT (T3516, SigmaAldrich, St. Louis, MO, USA) to a solution of fibrils. Fluorescence was monitored using a SpectraMax M2 (Molecular Devices) with excitation and emission slit widths set to $5 \mathrm{~nm}$, respectively. Spectra were obtained by scanning the fluorescence emission from 430 to $500 \mathrm{~nm}$, with excitation at $442 \mathrm{~nm}$. Fluorescence images were obtained using fluorescence microscopy (Nikon Eclipse 80i). An image was evaluated using the NIS-Elements F ver4.60 Imaging software.

2.4. Annexin $V$ Assay. Cells in the logarithmic phase were collected and cultured in a 24 -well plate at $4 \times 10^{4}$ cells/well. Cell survival was evaluated using an annexin $\mathrm{V}$ assay kit (Santa Cruz Biotechnology, CA, USA) following the manufacturer's procedure. The fluorescence was determined at $488 \mathrm{~nm}$ excitation and 525/30 emission using a Guava EasyCyte HT System (Millipore, Bedford, MA, USA).

2.5. Terminal Deoxynucleotidyl Transferase dUTP Nick EndLabeling (TUNEL) Assay. Cells in the logarithmic phase were collected and cultured in 6 -well plates at $3 \times 10^{5}$ cells/well. After treatment, neuronal apoptosis was assessed by using 

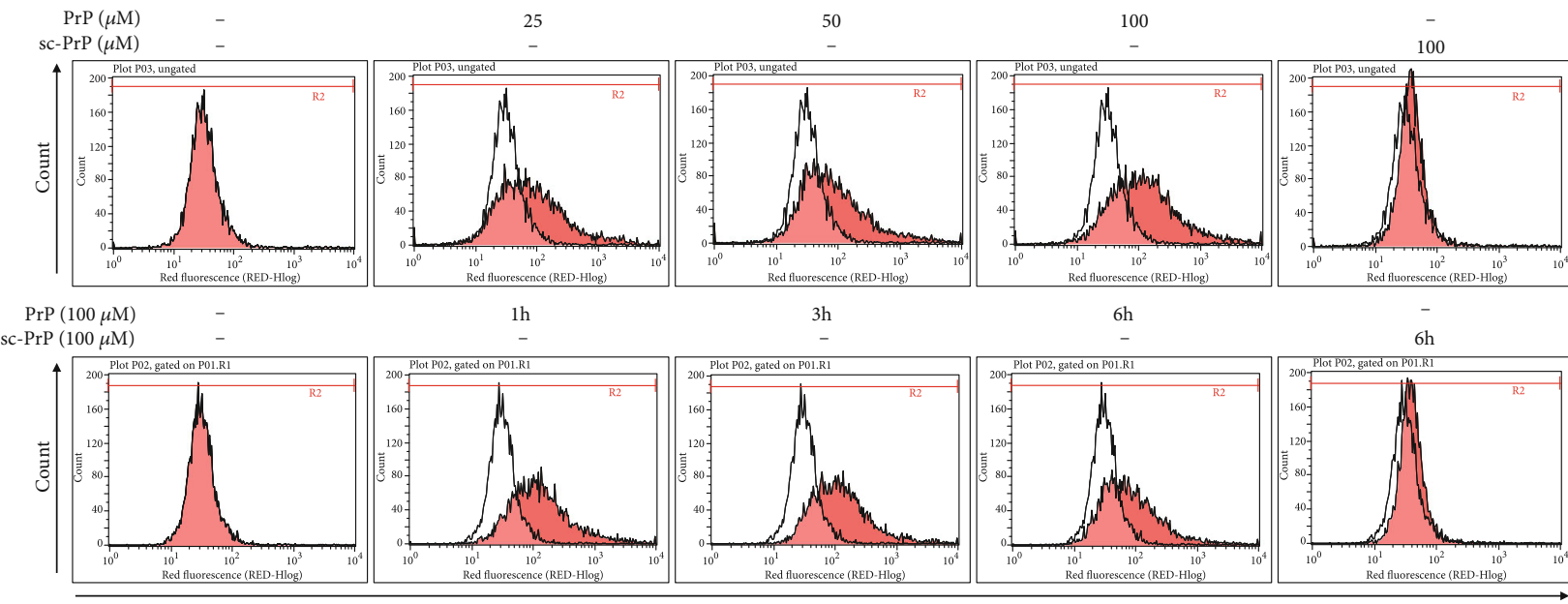

1h

$3 \mathrm{~h}$

$6 \mathrm{~h}$
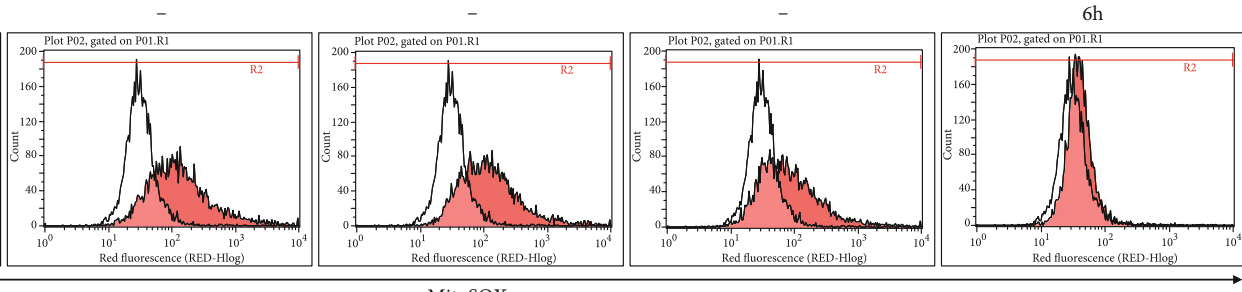

(a)

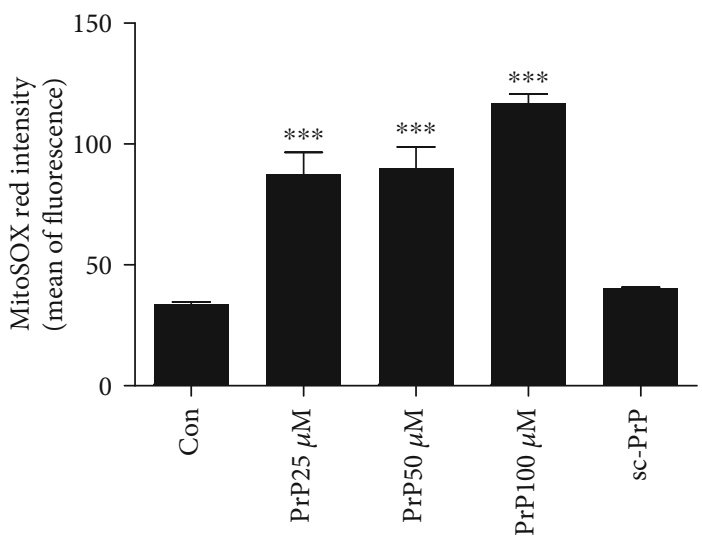

(b)

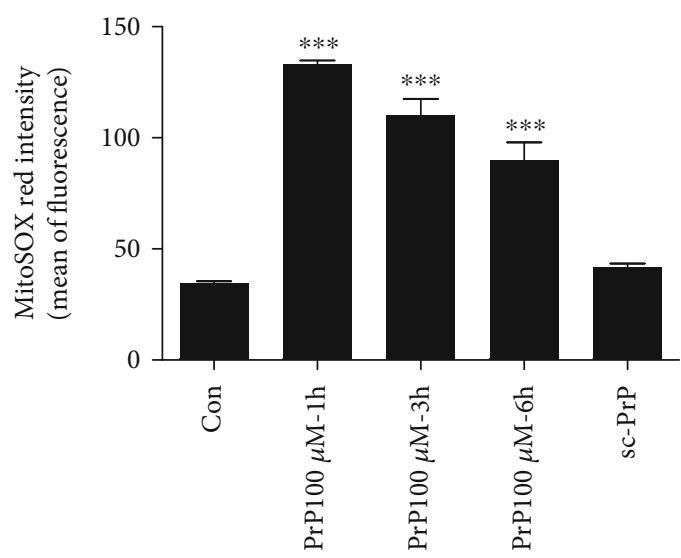

(c)


(d)

FIgure 2: Continued. 


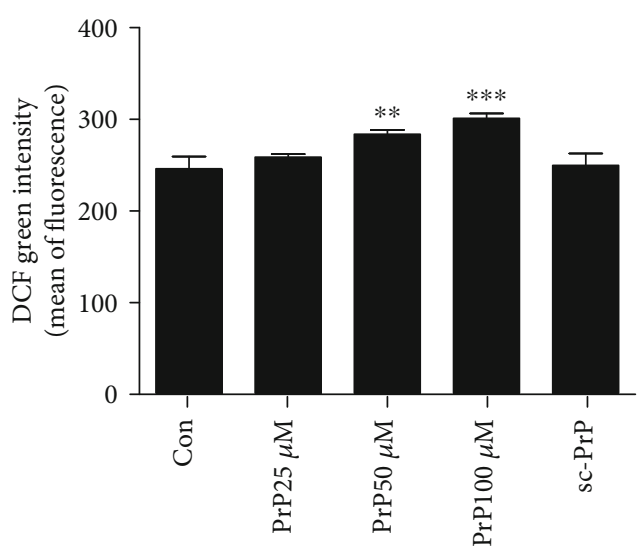

(e)

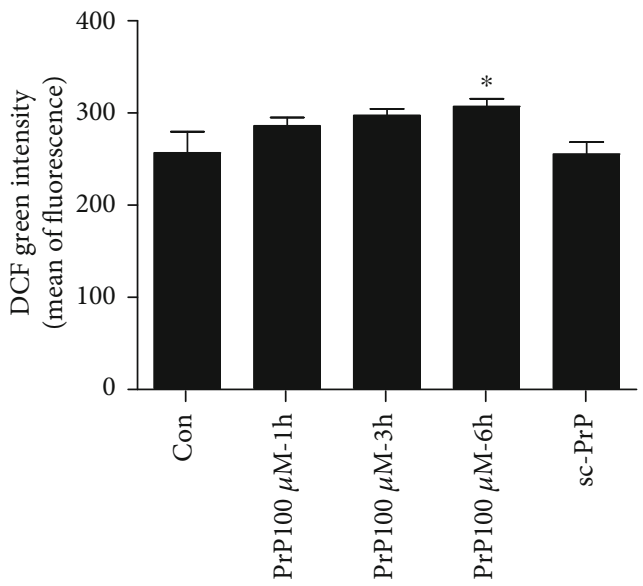

(f)

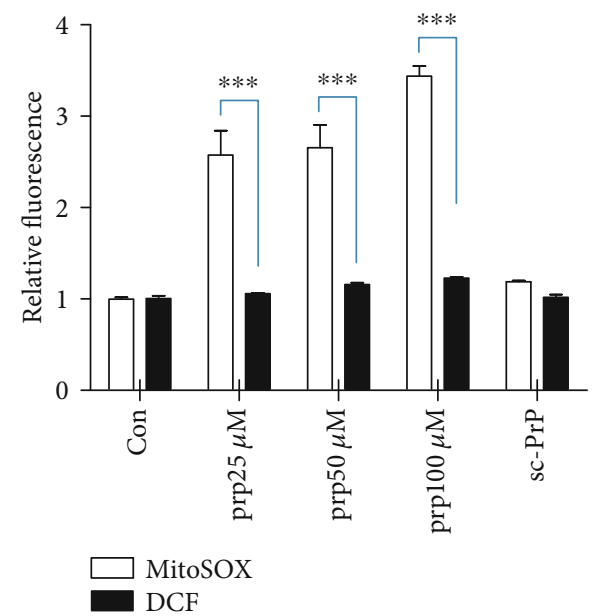

(g)

FIgURE 2: PrP (106-126) increased superoxide more than hydrogen peroxide. (a) Neuroblastoma cells (SK-N-SH) were exposed to PrP (106-126) or scrambled PrP in a dose- and time-dependent manner. Mitochondrial ROS was evaluated by a MitoSOX assay. (b, c) Bar graph showing the averages of the red fluorescence (MitoSOX) in a PrP dose- and time-dependent manner, respectively. Values represent the mean \pm SEM $(n=10) .{ }^{* * *} p<0.001$ vs. control. (d) SK-N-SH cells were treated with PrP $(106-126)$ or scrambled PrP in a dose- and time-dependent manner. Cytosol ROS was evaluated by a DCF assay. (e, f) Bar graph showing the averages of the green fluorescence (DCF) in a PrP dose- and time-dependent manner, respectively. (g) Relative MitoSOX and DCF fluorescence in a PrP dose-dependent manner. Values represent the mean \pm SEM $(n=10) .{ }^{*} p<0.05,{ }^{* *} p<0.01$, and ${ }^{* * *} p<0.001$ vs. control.

an ApoBrdU DNA Fragmentation Assay Kit (BioVision, Mountain View, CA, USA), consistent with the manufacturer's instructions. The nuclei were counterstained with PI.

2.6. Confocal Microscopy. In a confocal dish, SK-N-SH cells were incubated in HBSS medium (Gibco, Grand Island, NY, USA) containing $5 \mu \mathrm{M}$ MitoSOX and washed three times with HBSS. The cells were imaged on a Zeiss LSM710 microscope equipped with a standard set of lasers through a $63 x$ oil objective, installed at the Center for University Wide Research Facilities at Jeonbuk National University. The excitation wavelengths were 488,543, and $633 \mathrm{~nm}$. The bandpass filters were set at 500-550 (Alexa Fluor 488), 560-615 nm (Cy3, Alexa Fluor 568), and 650-750 nm (Alexa Fluor 647).

2.7. Cytosol and Mitochondrial ROS Assay. SK-N-SH cells were incubated in either HBSS containing $10 \mu \mathrm{M} 2^{\prime}, 7^{\prime}$ - dichlorodihydrofluorescein diacetate $\left(\mathrm{H}_{2}-\mathrm{DCFDA}\right)$ at $37^{\circ} \mathrm{C}$ for $30 \mathrm{~min}$ or $5 \mu \mathrm{M}$ MitoSOX at $37^{\circ} \mathrm{C}$ for $10 \mathrm{~min}$. Cells were transferred to a clear 96-well plate for flow cytometry analysis using a Guava EasyCyte HT System (Millipore, Bedford, MA, USA).

2.8. JC-1 Assay. SK-N-SH cells were incubated in HBSS containing $10 \mu \mathrm{M} \mathrm{JC}-1$ at $37^{\circ} \mathrm{C}$ for $30 \mathrm{~min}$. Cells were transferred to a clear 96-well plate for flow cytometry analysis using a Guava EasyCyte HT System (Millipore, Bedford, MA, USA). JC-1-stained cells on coverslips were imaged on a fluorescence microscope (Nikon Eclipse 80i).

2.9. Calcineurin Activity Assay. The calcineurin cellular activity assay kit (Enzo Life Sciences \#BML-AK816-0001, USA) was used consistent with the manufacturer's instructions to determine the phosphatase activity of calcineurin in SK-N$\mathrm{SH}$ cells [39]. In brief, the cells were lysed on ice in lysis buffer containing protease inhibitors. Phosphatase activity was 


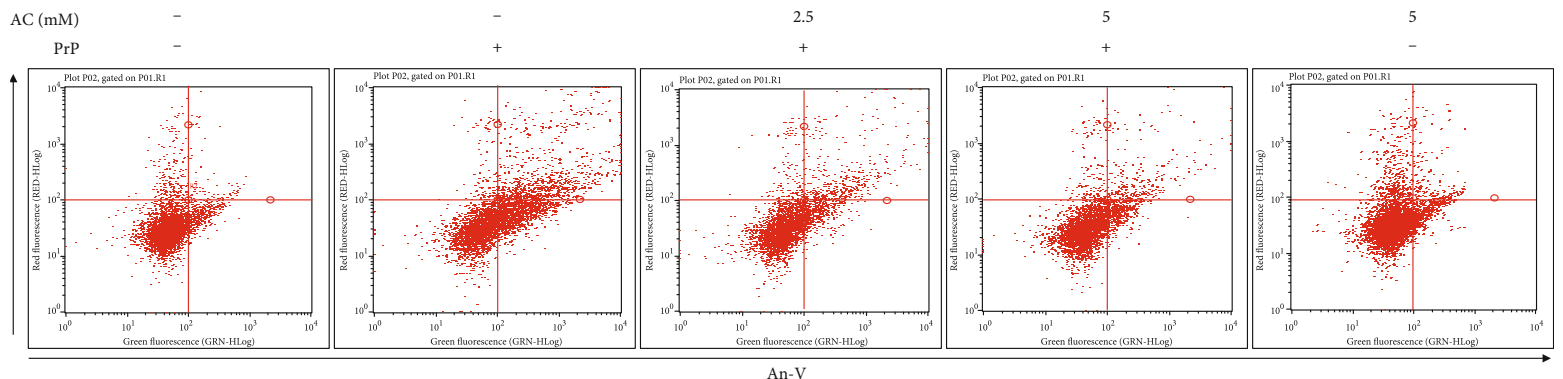

(a)

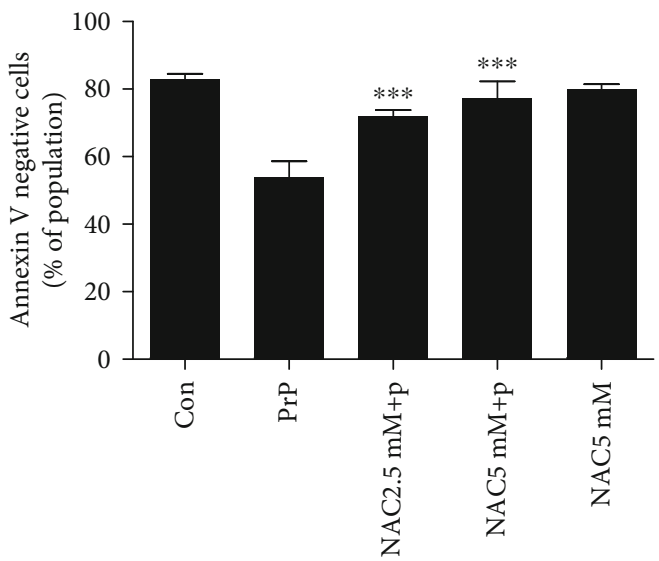

(b)

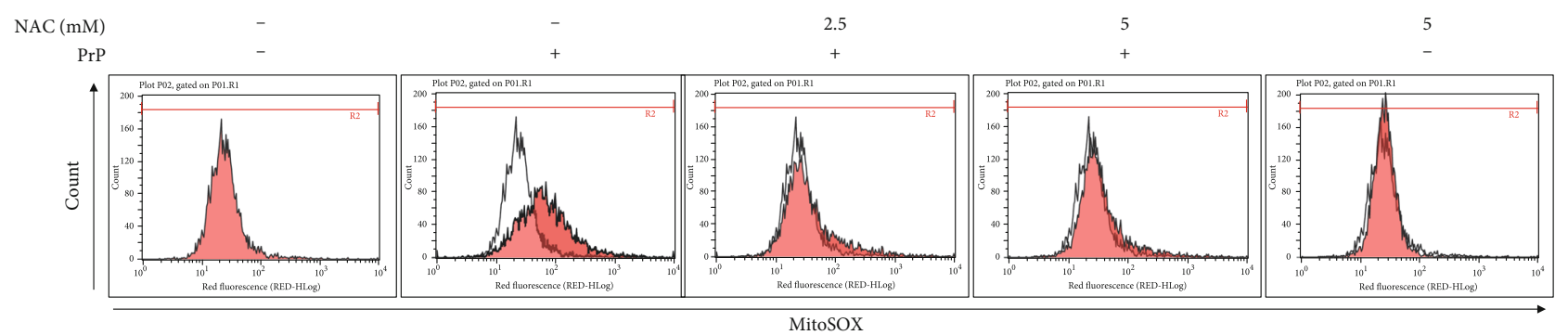

(c)

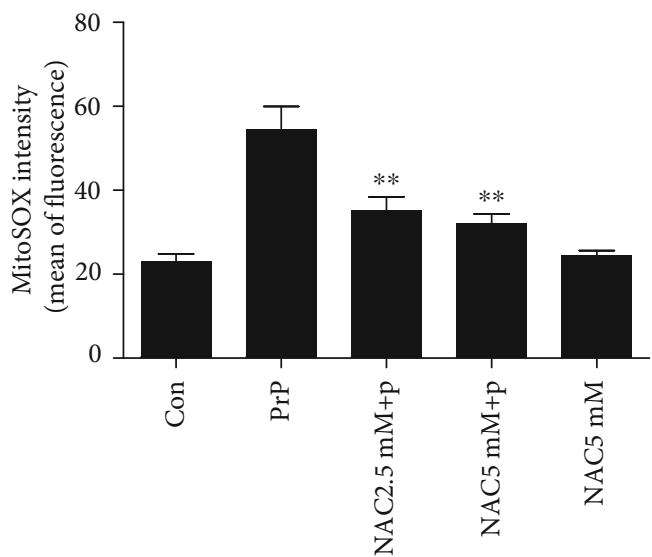

(d)

Figure 3: ROS scavenger treatment attenuated $\operatorname{PrP}$ (106-126)-mediated mitochondrial ROS and neurotoxicity. SK-N-SH cells were pretreated with NAC ( $N$-acetyl-l-cysteine) $(1 \mathrm{~h})$ at 2.5 and $5 \mathrm{mM}$ and then exposed to $100 \mu \mathrm{M} \operatorname{PrP}(106-126)$ for 6 hours. (a) Cell viability was evaluated by an annexin V assay using FITC-annexin V, which combines with phosphatidylserine on the plasma membrane during the apoptotic processes. (b) Bar graph showing the averages of the annexin V-negative cells. Values represent the mean \pm SEM $(n=10)$. ${ }^{* * *} p<0.001$ vs. PrP. (c) Mitochondrial ROS was evaluated by a MitoSOX assay. (d) Bar graph showing the averages of the red fluorescence (MitoSOX). Values represent the mean \pm SEM $(n=10) .{ }^{* *} p<0.01$ vs. PrP. 

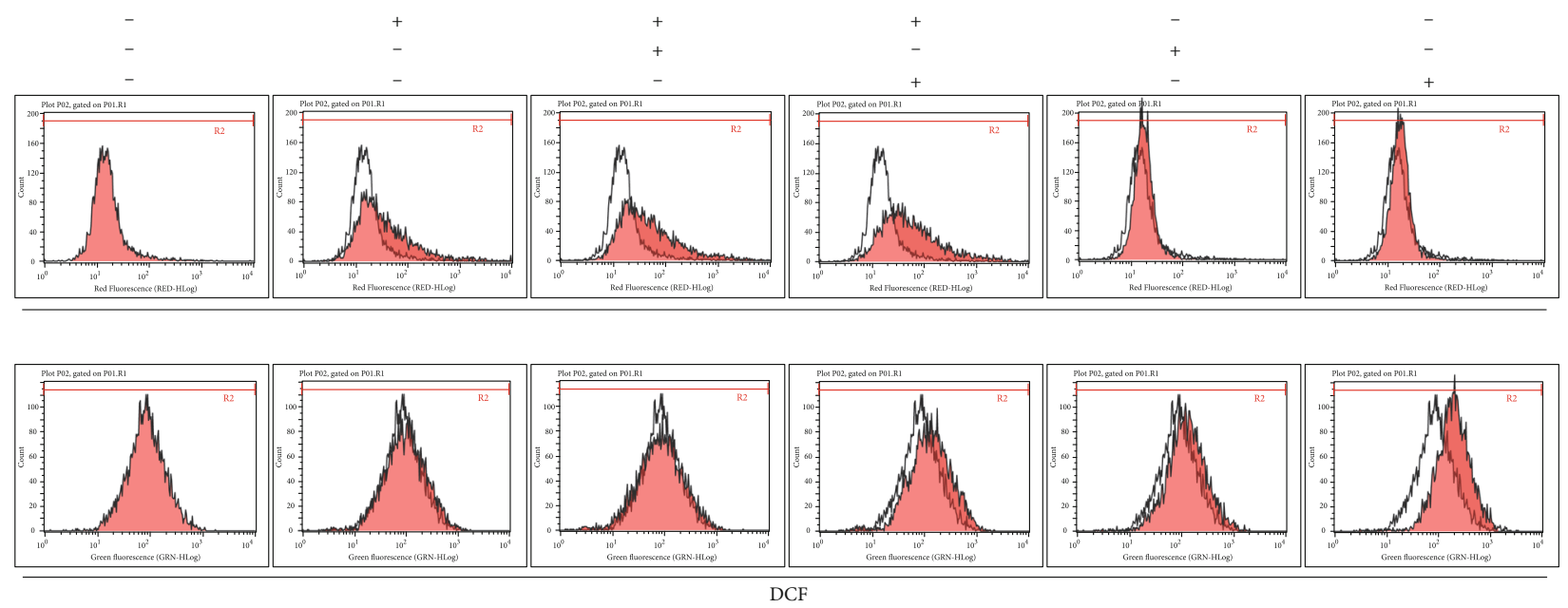

(a)

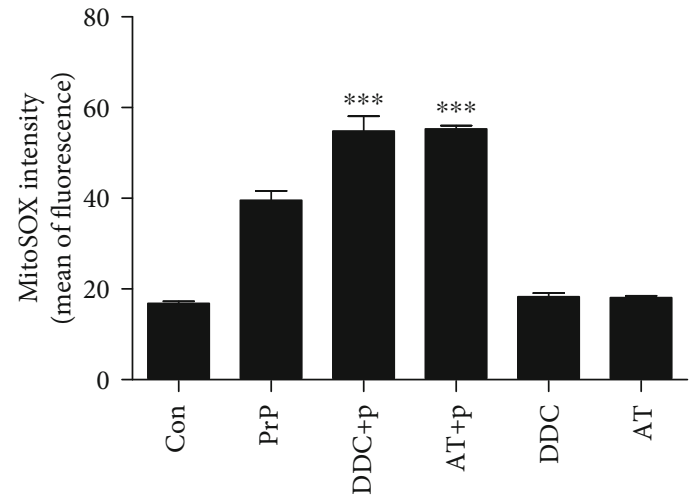

(b)

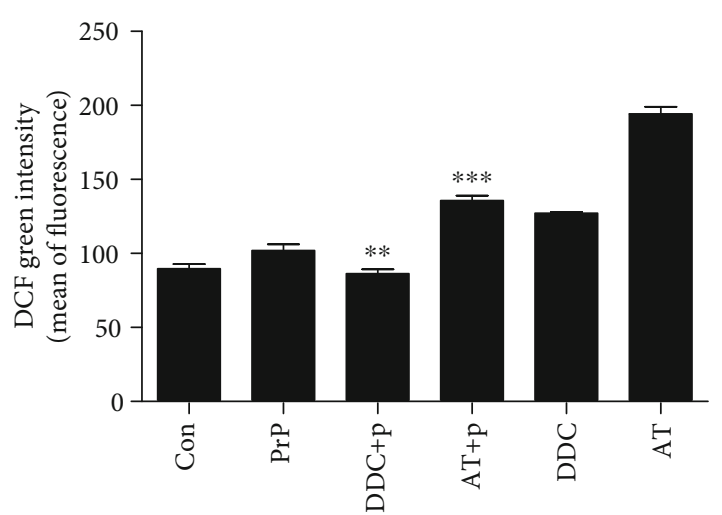

(c)

Figure 4: PrP (106-126) did not influence SOD or catalase enzyme. SK-N-SH cells were pretreated with DDC (diethyldithiocarbamate) (1 h) or AT (3-amino-1,2,4-triazole) (24h) and then exposed to $100 \mu \mathrm{M} \operatorname{PrP}(106-126)$ for 6 hours. (a) Mitochondrial ROS was evaluated by a MitoSOX assay, and cytosol ROS was evaluated by a DCF assay. (b) Bar graph showing the averages of the red fluorescence (MitoSOX). (c) Bar graph showing the averages of the green fluorescence (DCF). Values represent the mean $\pm \operatorname{SEM}(n=10) .{ }^{* *} p<0.01,{ }^{* * *} p<0.001$ vs. $\operatorname{PrP}$.

quantified by detecting free phosphate released from the reaction by measuring the absorbance of malachite green (OD $620 \mathrm{~nm}$ ) using a SpectraMax M2 (Molecular Devices).

2.10. Western Blot Analysis. Cells in the logarithmic phase were collected and cultured in a 6 -well plate at $3 \times 10^{5}$ cells/ well. The western blot method has been described in detail previously [20]. We used a nuclear/cytosol fractionation kit (\#K266, BioVision). After treatments, cells were washed with PBS and lysed in lysis buffer (25 mM HEPES (4-(2-hydroxyethyl)-1-piperazineethanesulfonic acid), pH 7.4, $100 \mathrm{mM}$ $\mathrm{NaCl}, 1 \mathrm{mM}$ ethylene diamine tetra acetic acid (EDTA), $5 \mathrm{mM} \mathrm{MgCl} 2,0.1 \mathrm{mM}$ dithiothreitol (DTT), and a protease inhibitor mixture). Equal quantities of proteins (more than $15 \mu \mathrm{g} / \mu \mathrm{L})$ in the nuclear or cytosolic extracts were electrophoretically resolved on a $10 \%$ sodium dodecyl sulfate (SDS) poly-acrylamide gel and transferred to a nitrocellulose membrane. Immunoreactivity was detected through consecutive incubation with blocking solution using 5\% skim milk and primary antibodies, followed by the corresponding horseradish peroxidase-conjugated secondary antibodies, and finally developed using enhanced chemiluminescence substances (i.e., west save gold detection kit (LF-QC0103, AbFrontier Inc.)). The primary antibodies (anti-calcineurin at a dilution of 1:1000 (ab109412, Abcam plc), antiNFAT1 at a dilution of 1:1000 (\#5861, Cell Signaling), anti-lamin A/C at a dilution of $1: 10000$ (ab108595, Abcam plc), and anti- $\beta$-actin at dilution of 1:5000 (A5441, Sigma Aldrich)) were diluted with antibody solution (1\% skim milk in TBST). Images were inspected using a Fusion FX7 imaging system (Vilber Lourmat, Torcy Z.I. Sud, France). Densitometry of the signal bands was evaluated using the Bio-1D software (Vilber Lourmat, Marne La Vallee, France).

2.11. Statistical Analysis. Results are expressed as the means \pm standard error of the mean (SEM) from at least three independent replicates. All experiments were analyzed by the one-way analysis of variance (ANOVA). Comparisons of three or more groups were made using Tukey's posttests. All statistical analyses were implemented with GraphPad Prism version 5.0. $p$ values $\left({ }^{*} p<0.05,{ }^{* *} p<0.01\right.$, or $\left.{ }^{* * *} p<0.001\right)$ were considered statistically significant. 


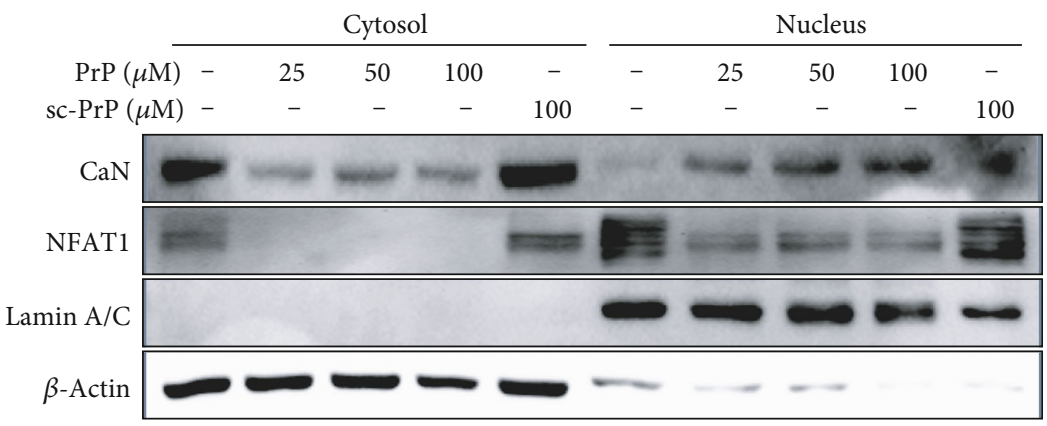

(a)

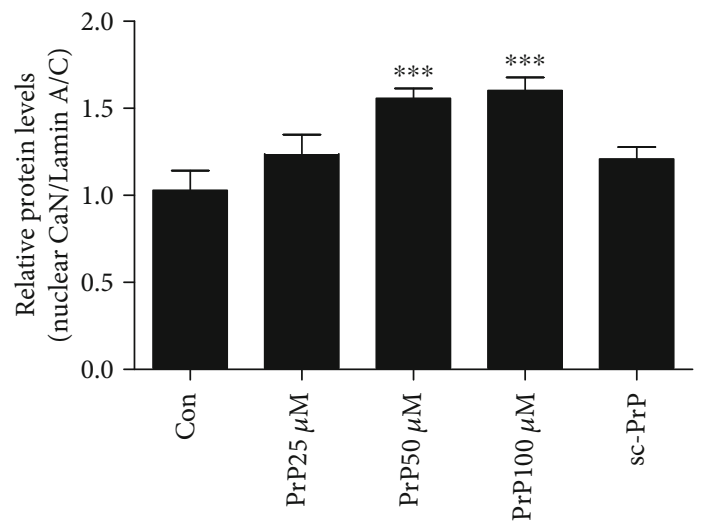

(b)

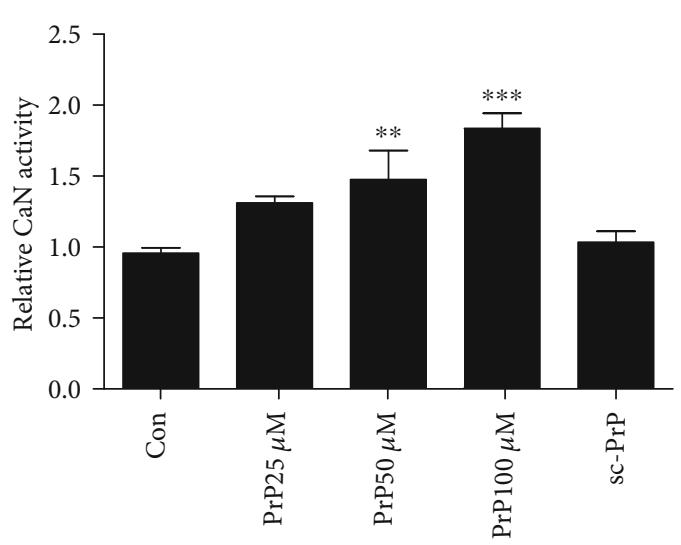

(c)

Figure 5: PrP (106-126) treatment upregulated calcineurin (CaN) activity. SK-N-SH cells were exposed to PrP (106-126) or scrambled PrP in a dose-dependent manner for 5 hours. (a) Cytosolic and nuclear fractions obtained from SK-N-SH cells induced for human calcineurin expression are analyzed by western blot with antibodies for $\mathrm{CaN}$, for the cytosolic $\beta$-actin marker, and for the nuclear lamin $\mathrm{A} / \mathrm{C}$ marker. (b) Bar graph representing the average nuclear $\mathrm{CaN}$ protein levels. The expression data were normalized to lamin $\mathrm{A} / \mathrm{C}$ expression. The expression levels were evaluated by quantifying the protein bands, depicted by densitometric values beside the blot. Values represent the mean $\pm \operatorname{SEM}(n=5) .{ }^{* *} p<0.01,{ }^{* * *} p<0.001$ vs. control.

\section{Results}

3.1. Prion Peptide 106-126 Generated More Mitochondrial ROS than Cytosolic ROS. Prion peptide 106-126 has previously been known to induce neurotoxicity as a result of its ability to form aggregates [46]. Thioflavin-T (ThT) binding was employed to confirm the amyloid fibrils formed by our PrP 106-126 peptides. Binding of ThT to polypeptide chains is specific for the cross- $\beta$ structure of amyloid fibrils. We identified binding of ThT to prion peptide and amyloid $\beta$ by fluorescence microscopy (Figure 1(a)). An increase in ThT fluorescence at $430-500 \mathrm{~nm}$ is observed, as shown in Figure 1(b), supporting a cross- $\beta$ structure for PrP 106-126 fibrils.

Although there is prior research that has suggested that prion peptide could induce cellular ROS in neurons, ROS's origin has not been examined. To determine this, we performed mitochondrial and cytosolic ROS detection experiments using both DCF and MitoSOX assays. PrP (106-126)mediated mitochondrial ROS generation rose dose- and time-dependently in SK-N-SH neuroblastoma cells, whereas scrambled PrP did not increase mitochondrial ROS (Figures 2(a)-2(c)). PrP (106-126) slightly increased cytosolic ROS generation dose- and time-dependently (Figures 2(d)2(f)). We determined that PrP (106-126) upregulated mito- chondrial ROS more than cytosolic ROS (Figure 2(g)), suggesting that PrP (106-126) influences mitochondrial ROS and mitochondrial dysfunction in neuronal cells.

3.2. Prion Peptide 106-126 Promotes Neuronal Apoptosis through Mitochondrial ROS Generation. We examined whether PrP-induced mitochondrial ROS influenced neurotoxicity using the ROS scavenger NAC. NAC treatment attenuated PrP-mediated neuronal apoptosis dose-dependently (Figures 3(a) and 3(b)). We determined that NAC, as a reactive oxygen species (ROS) scavenger, decreased $\mathrm{PrP}$ mediated mitochondrial ROS generation (Figures 3(c) and $3(\mathrm{~d})$ ), confirming that the prion peptide induces neuronal apoptosis through mitochondrial ROS generation.

Sinclair et al. have suggested that the prion aggravates an apoptotic pathway through mitochondrial dysfunction and mislocalisation of SOD2 to cytosolic caspases [47]. We investigated the impact of $\operatorname{PrP}(106-126)$ on superoxide dismutases (SODs) and a catalase enzyme using an SOD inhibitor (diethyldithiocarbamate; DDC) and a catalase inhibitor (3amino-1,2,4-triazole; AT). We determined that DDC and AT increased mitochondrial ROS, including superoxide, which had already been raised by PrP (106-126), meaning that this prion peptide did not influence SOD function (Figures 4(a) and 4(b)). DDC decreased cytosolic ROS such 


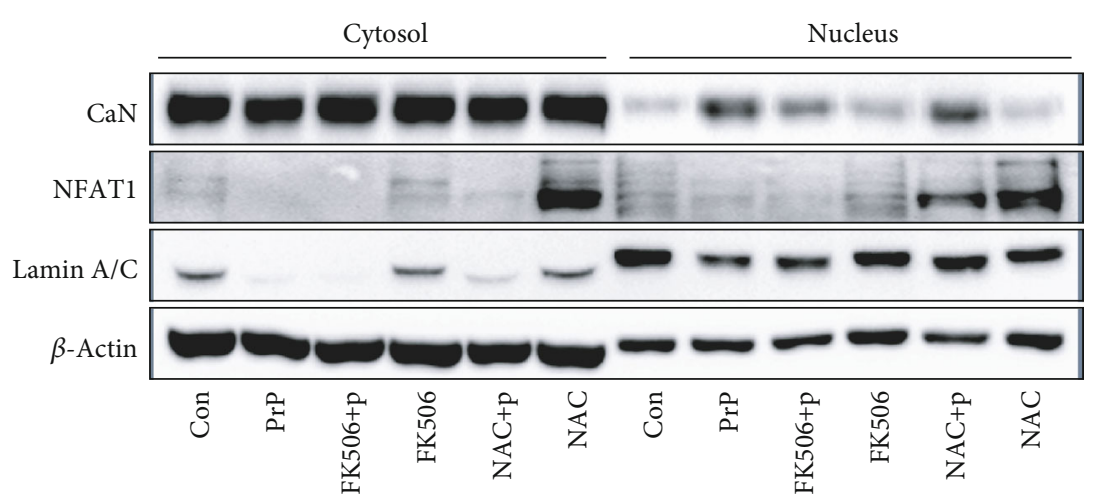

(a)

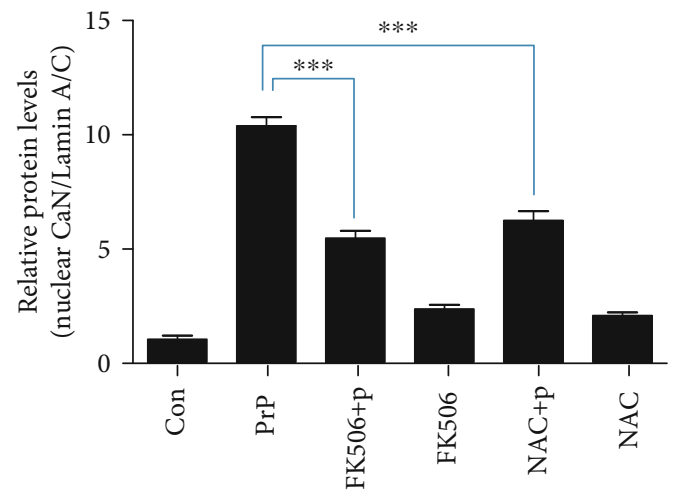

(b)

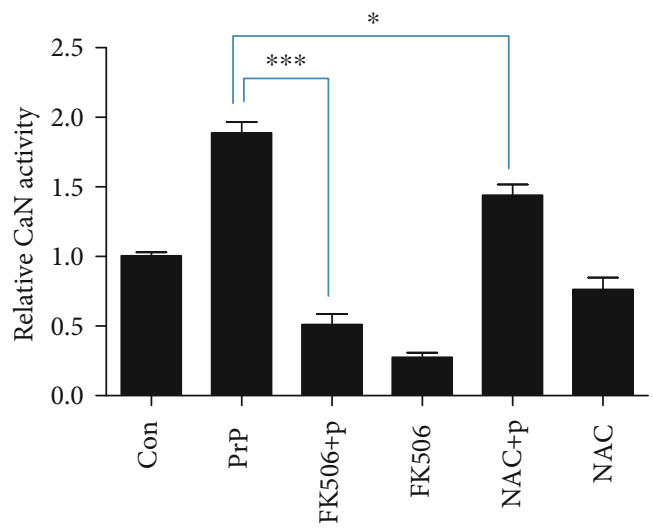

(c)

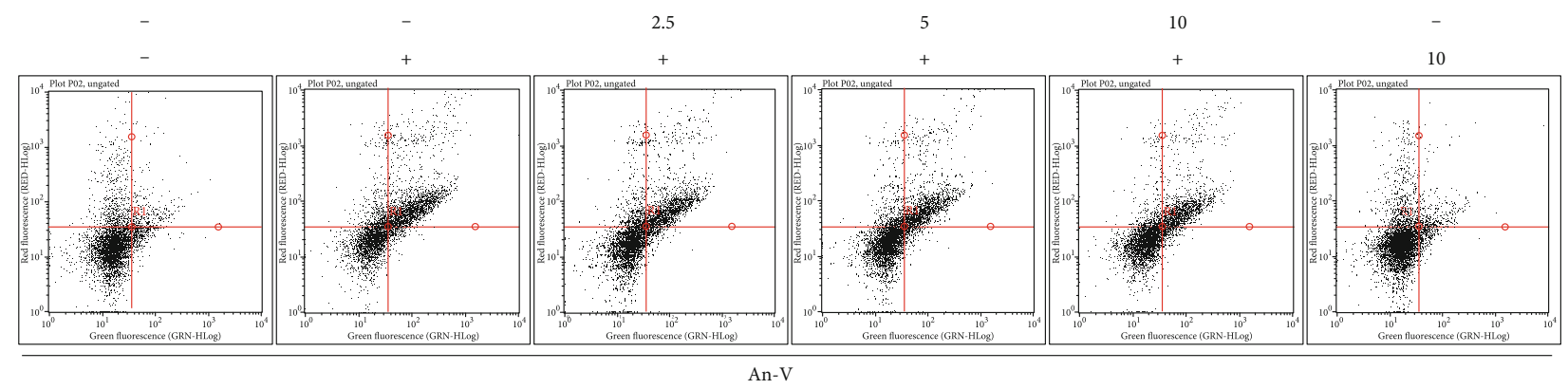

(d)

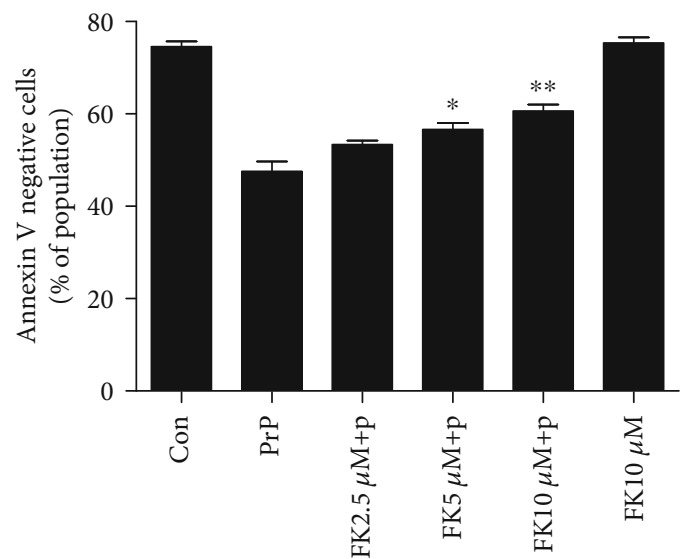

(e)

FIgURe 6: Continued. 


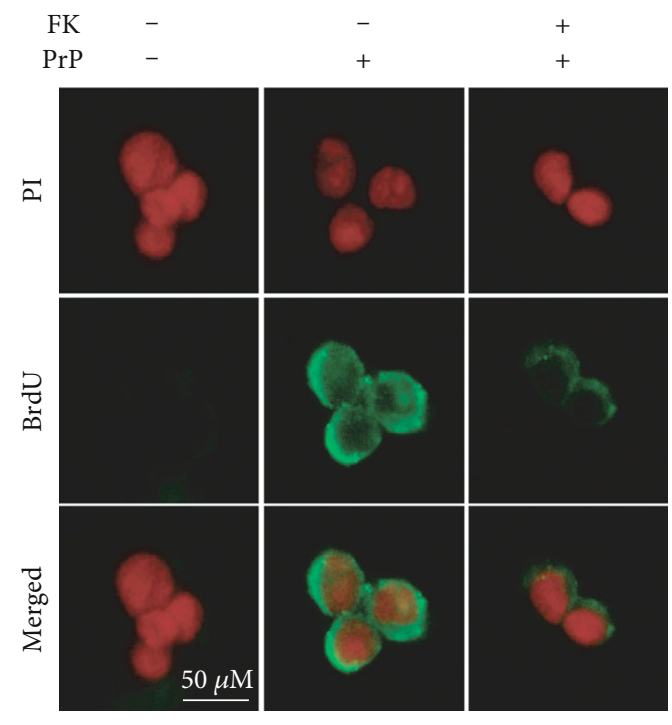

(f)

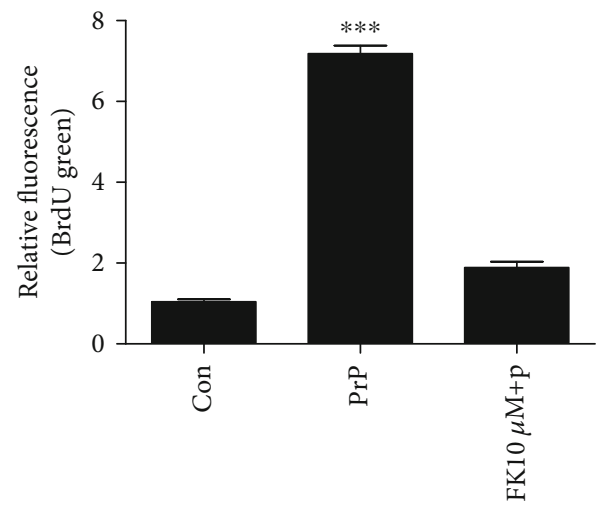

(g)

FIgURE 6: FK506 treatment attenuates PrP (106-126)-induced neurotoxicity via CaN inhibition. SK-N-SH cells were pretreated with FK506 $(10 \mu \mathrm{M}, 1 \mathrm{~h})$ or NAC $(5 \mathrm{mM}, 1 \mathrm{~h})$ and then exposed to $100 \mu \mathrm{M} \operatorname{PrP}(106-126)$ for 5 hours. (a) Cytosolic and nuclear fractions obtained from SK-N-SH cells induced for human calcineurin expression are analyzed by western blot with antibodies for CaN, for the cytosolic $\beta$-actin marker, and for the nuclear lamin A/C marker. (b) Bar graph representing the average nuclear CaN protein levels. The expression data were normalized to lamin A/C expression. (c) CaN activity was evaluated by a CaN activity assay. Values represent the mean \pm SEM $(n=5)$. ${ }^{*} p<0.05,{ }^{* * *} p<0.001$ vs. PrP. (d) SK-N-SH cells were pretreated with FK506 (1 h) in a dose-dependent manner and then exposed to $100 \mu \mathrm{M} \operatorname{PrP}$ (106-126) for 6 hours. Cell viability was evaluated by an annexin V assay using FITC-annexin V, which combines with phosphatidylserine on the plasma membrane during apoptotic processes. (e) Bar graph showing the averages of the annexin V-negative cells. Values represent the mean \pm SEM $(n=10) .{ }^{*} p<0.05,{ }^{* *} p<0.01$ vs. PrP. (f) TUNEL-positive (green) immunofluorescence images were obtained after exposure to $100 \mu \mathrm{M} \operatorname{PrP}(106-126)(6 \mathrm{~h})$ in the absence or presence of FK506 $(10 \mu \mathrm{M}, 1 \mathrm{~h})$. The cell nuclei were counterstained with PI (red). (g) Bar graph showing the relative mean values of the green fluorescence (BrdU). Values represent the mean \pm SEM $(n=5)$. ${ }^{* * *} p<0.001$ vs. control.

as hydrogen peroxide while AT increased cytosolic ROS that had already been raised by $\operatorname{PrP}(106-126)$ (Figures 4(a) and 4(c)), meaning that $\operatorname{PrP}$ (106-126) did not impair the SOD and the catalase. These results indicate that the prion peptide increased mitochondrial ROS production through pathways other than SOD and catalase impairment.

\subsection{Prion Peptide Induced Neurotoxicity via CaN Activation.}

In a previous study, we demonstrated how $\operatorname{PrP}$ (106-126) induces neurotoxicity through calcium alteration [40]. In this study, we checked whether PrP (106-126) alters CaN in neuronal cells. PrP (106-126) increased nuclear CaN translocation dose-dependently (Figures 5(a) and 5(b)). We identified $\mathrm{CaN}$ activation by prion peptide treatment using a $\mathrm{CaN}$ phosphatase activity assay (Figure 5(c)). We also identified NFAT1 as a transcriptional factor related to $\mathrm{CaN}$, and $\operatorname{PrP}$ (106-126) decreased NFAT1 protein expression in both the nucleus and cytosol (Figure 5(a)). This result suggests that NFAT is not dependent on CaN.

$\operatorname{PrP}(106-126)$-increased $\mathrm{CaN}$ was reduced by the $\mathrm{CaN}$ inhibitor FK506 and ROS scavenger NAC (Figures 6(a) and 6(b)). CaN activity was also decreased by FK506 and NAC (Figure 6(c)). NFAT1 is decreased in PrP-treated cells, and FK506 also decreased NFAT1 protein expression (Figure 6(a)). Based on these results, we suggest that $\mathrm{CaN}$ and ROS influence each other through a feedback loop.
To investigate the effect of prion peptide-mediated CaN activation on neuronal apoptosis, we employed the $\mathrm{CaN}$ inhibitor FK506. We found that FK506 attenuated prion peptide-induced neuronal apoptosis dose-dependently using an An-V/PI assay (Figures 6(d) and 6(e)). In addition, we identified that FK506 repressed PrP-mediated DNA strand damage using a TUNEL assay (Figures 6(f) and 6(g)). We suggest that $\operatorname{PrP}(106-126)$ induces neuronal apoptosis through $\mathrm{CaN}$ activation.

3.4. CaN Activation by Prion Peptide Promoted Mitochondrial Dysfunction. To investigate the effect of prion peptide inducing $\mathrm{CaN}$ activation on mitochondrial function, we ran an experiment using the MitoSOX and JC-1 assay using FK506. We used the MitoSOX assay to determine that treatment with FK506 decreased the mitochondrial ROS in PrP-treated neuronal cells (Figures 7(a) and 7(b)). We also imaged the MitoSOX using confocal microscopy (Figure 7(c)). Further, we determined that FK506 repressed the prion peptide-induced mitochondrial dysfunction using the JC-1 assay (Figures 7(d) and 7(e)) and fluorescence microscopy (Figure 7(f)). These results demonstrate that prion peptide-mediated neuronal apoptosis is dependent on $\mathrm{CaN}$ activation and mitochondrial ROS and that $\mathrm{CaN}$ is a key regulator of prion peptide-mediated ROS generation and neurotoxicity. In sum, our results suggest that prion 


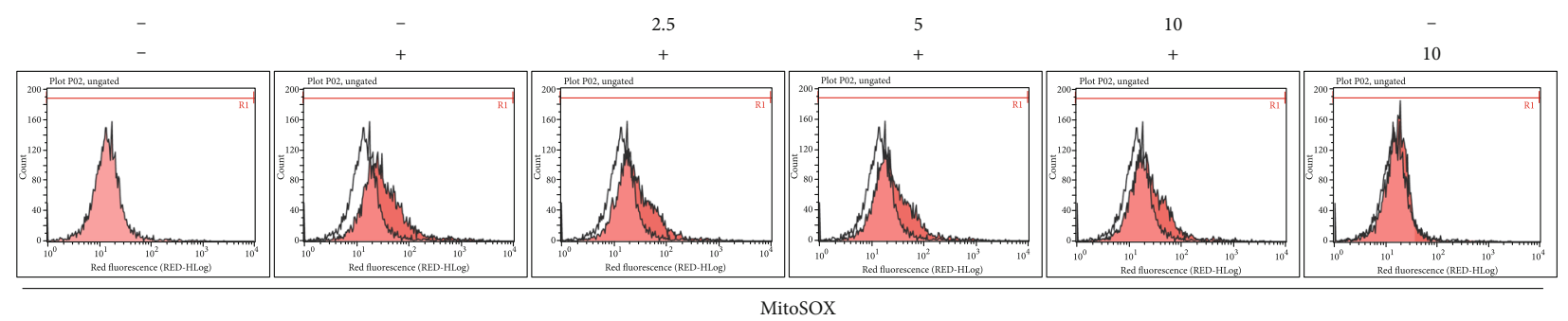

(a)



(b)

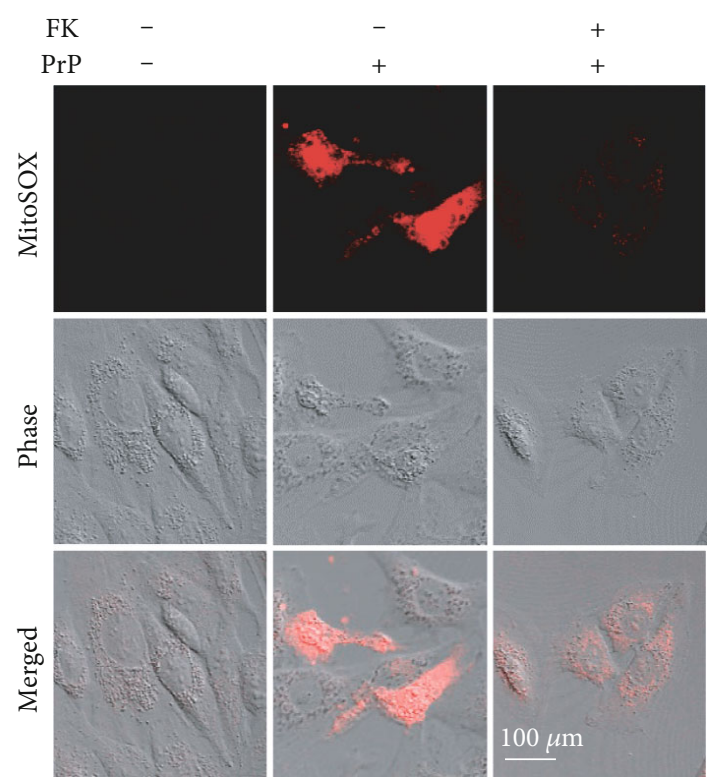

(c)
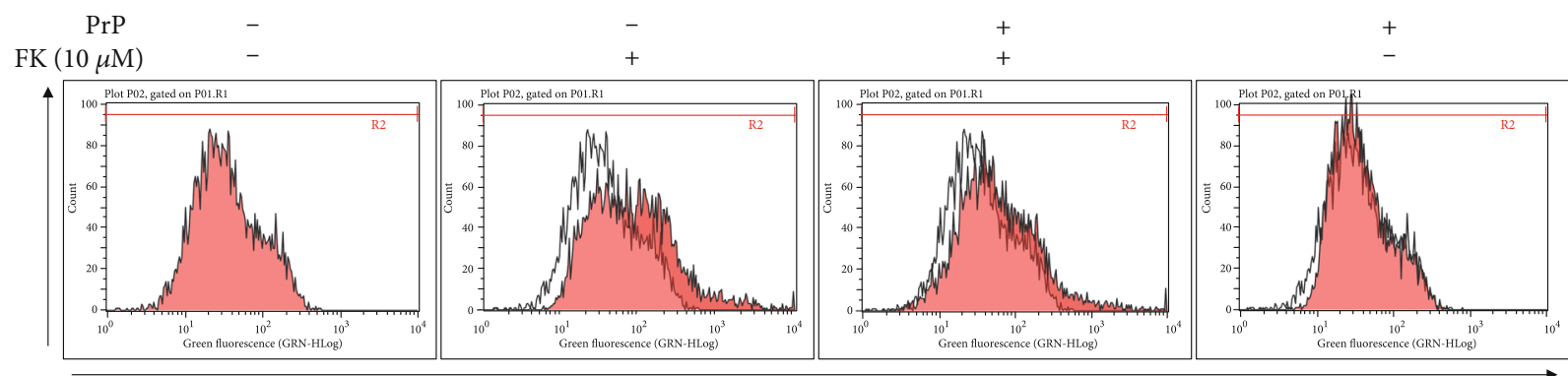

JC-1 monomer (green)

(d)

Figure 7: Continued. 




(e)


(f)

Figure 7: PrP (106-126)-mediated calcineurin activation induced neurotoxicity via mitochondrial dysfunction. SK-N-SH cells were pretreated with FK506 $(1 \mathrm{~h})$ and then exposed to $100 \mu \mathrm{M} \operatorname{PrP}(106-126)$ for 6 hours. (a) Mitochondrial ROS was evaluated by a MitoSOX assay. (b) Bar graph showing the averages of the red fluorescence (MitoSOX). Values represent the mean \pm SEM $(n=10)$. ${ }^{* *} p<0.01,{ }^{* * *} p<0.001$ vs. PrP. (c) MitoSOX fluorescence images were obtained after exposure to $100 \mu \mathrm{M} \operatorname{PrP}(106-126)(6 \mathrm{~h})$ in the absence or presence of FK506 $(10 \mu \mathrm{M}, 1 \mathrm{~h})$. (d) Mitochondrial membrane potential was evaluated by a JC-1 assay using flow cytometry. In green fluorescent colors, JC-1 accumulates as green monomers in the mitochondria of cells with impaired mitochondrial membrane potential function. (e) Bar graph showing the averages of the green fluorescence (JC-1 monomers). Values represent the mean \pm SEM $(n=10){ }^{* *} p<0.01$ vs. PrP. (f) JC-1 fluorescence images were obtained after exposure to $100 \mu \mathrm{M}$ PrP $(106-126)(6 \mathrm{~h})$ in the absence or presence of FK506 $(10 \mu \mathrm{M}, 1 \mathrm{~h})$.

peptide (106-126) induces mitochondrial ROS and neuronal apoptosis through $\mathrm{CaN}$ activation in neuronal cells.

\section{Discussion}

Neurotoxic PrP 106-126 preserves biochemical substances similar to those of the abnormally folded prion protein PrPsc, together with protease resistance, $\beta$-sheet construction, and cytotoxicity [13, 48-50]. Previous literature has investigated prion pathogenesis and neurotoxic pathways using Rocky Mountain Laboratory (RML) strain and antibody-derived anti-PrP ligands in in vivo models [51-53]. Typical neurodegenerative fluctuations in prion diseases have been observed in the absence of detectable PrPsc, suggesting that prion disorders are caused by alternative mechanisms of neuronal damage, as well as PrPsc [54, 55]. PrP 106-126 has been suggested as one such alternative contributor to the pathogenic and molecular properties of PrPsc [56]. Although the functional and mechanical properties of prion protein remain unclear, a number of studies have suggested that prions are triggered by accumulation in the brain of amyloid plaque PrPsc, similar to amyloid- $\beta$ in Alzheimer's disease $[5,57,58]$.

$\mathrm{CaN}$ was recently suggested as an important therapeutic target for the potential treatment of neurodegenerative diseases $[59,60]$. CaN is abundant in the synaptic terminals and cytosol of neurons, which suggest that it may play a critical role in the maintenance of cellular homeostasis during calcium alteration $[44,45]$. Hyperactivation of $\mathrm{CaN}$ is implicated in a reversible neuronal apoptotic pathway involving
Bcl-2 family proteins $[61,62]$. Moreover, CaN plays an essential role in modulating gene expression, including cAMPresponse element binding protein (CREB) and nuclear factor of activated T-cell (NFAT), as well as regulating calcium alteration [44, 63-65]. Since phosphorylated CREB and dephosphorylated NFAT4 translocate into the nucleus and induce gene expression, several studies have observed CaN protein expression in nuclear fraction [66-68]. Consistent with these studies, we identified translocation of $\mathrm{CaN}$ into a nucleus caused by prion peptide treatment in neuronal cells (Figure 4). Other literature has suggested that $\mathrm{CaN}$ is activated by cleavage of the autoinhibitory domain that transforms it into a constitutively active form [69-71]. We could not observe any meaningful cleavage form $\mathrm{CaN}$ in prion peptide-treated neuronal cells (not shown). Accordingly, we suggest that prion peptide may induce CaN activation by nuclear translocation. However, the association between $\mathrm{CaN}$ and neurodegenerative progression remains contentious [72-74].

In our previous study, we prove that prion peptide 106126 induced neurotoxicity through the AMPK-CaNautophagy pathway $[39,40]$. AMPK has been recognized in the past few years to act as a crucial integrator of autophagy and mitochondrial homeostasis by controlling various aspects of the cellular life cycle [75]. In this study, our goal is to investigate what kind of ROS is generated in prionmediated neurotoxic conditions and elucidate the relationship between this ROS and CaN pathway in prion diseases. In future, further studies are required to investigate the role 
of AMPK in this mitochondrial ROS generation as well as apoptosis in prion diseases.

We observed that the expression of NFAT1 was decreased in the nucleus in PrP-treated condition (Figure 5(a)). CaN is well known to the phosphatase that promotes NFAT nuclear import, and its activity is regulated not only by upstream $\mathrm{Ca}^{2+}$ and calmodulin but also by multiple endogenous calcineurin inhibitors [76]. However, the specific role of each NFAT member in gene transcription during the cell cycle and apoptosis is not fully clear, especially in neurons [77]. In our results, NFAT1 alteration was not dependent on the $\mathrm{CaN}$ (Figures 5 and 6), but rather the total amount of NFAT1 of whole cell lysates was decreased in PrP-treated cells. Further studies will be needed to discover how prion peptide decreased NFAT1 protein expression in cellular pathways.

We demonstrated ROS generation using the MitoSOX and DCF assay. A MitoSOX usually indicates mitochondrial ROS, and DCF indicates cytosolic ROS. In Figure 3(c), AT alone induces DCF generation as compared to control. AT was used as a catalase inhibitor that prevents hydrogen peroxide to water $\left(\mathrm{H}_{2} \mathrm{O}\right)$ substitution. DDC and AT affected PrP-induced DCF generation. However, we focused on PrP-induced mitochondrial ROS (MitoSOX) because DCF generation by prion peptide was insignificant.

Several studies have reported that $\mathrm{CaN}$ activity is regulated by $\mathrm{Ca}^{2+}$ as well as by oxidative stress conditions $[45,78]$. Accordingly, we investigated the relationship between $\mathrm{CaN}$ activity and intracellular ROS. Prior literature has suggested that PrP 106-126 induces intracellular ROS $[31,79]$.

\section{Conclusion}

Our results prove that $\operatorname{PrP} 106-126$ generates more mitochondrial ROS than cytosolic ROS and PrP-mediated CaN activation regulated mitochondrial ROS in neuronal cells. These results also suggest that PrP-induced mitochondrial ROS production triggers CaN activation partially as circulating feedback action, and the regulation of $\mathrm{CaN}$ may be a practical therapeutic treatment for prion disease.

\section{Data Availability}

The data used to support the findings of this study are available from the corresponding author upon request.

\section{Conflicts of Interest}

The authors declare that they have no competing interests.

\section{Authors' Contributions}

J.H.M. and S.Y.P. designed and executed the study, analyzed the data, and wrote the manuscript. All authors have read and approved the final manuscript.

\section{Acknowledgments}

This study was supported by a grant from the National Research Foundation of Korea (NRF) funded by the Ministry of Education (2019R1A6A1A03033084).

\section{References}

[1] A. Aguzzi and C. Haass, "Games played by rogue proteins in prion disorders and Alzheimer's disease," Science, vol. 302, no. 5646, pp. 814-818, 2003.

[2] M. Costanzo and C. Zurzolo, "The cell biology of prion-like spread of protein aggregates: mechanisms and implication in neurodegeneration," The Biochemical Journal, vol. 452, no. 1, pp. 1-17, 2013.

[3] C. Scheckel and A. Aguzzi, "Prions, prionoids and protein misfolding disorders," Nature Reviews Genetics, vol. 19, no. 7, pp. 405-418, 2018.

[4] C. Zhu, U. S. Herrmann, J. Falsig et al., "A neuroprotective role for microglia in prion diseases," The Journal of Experimental Medicine, vol. 213, no. 6, pp. 1047-1059, 2016.

[5] C. Zhu, B. Li, K. Frontzek, Y. Liu, and A. Aguzzi, "SARM1 deficiency up-regulates XAF1, promotes neuronal apoptosis, and accelerates prion disease," The Journal of Experimental Medicine, vol. 216, no. 4, pp. 743-756, 2019.

[6] B. C. Yoo, K. Krapfenbauer, N. Cairns, G. Belay, M. Bajo, and G. Lubec, "Overexpressed protein disulfide isomerase in brains of patients with sporadic Creutzfeldt-Jakob disease," Neuroscience Letters, vol. 334, no. 3, pp. 196-200, 2002.

[7] J. A. Moreno, M. Halliday, C. Molloy et al., "Oral treatment targeting the unfolded protein response prevents neurodegeneration and clinical disease in prion-infected mice," Science translational medicine, vol. 5, no. 206, p. 206ra138, 2013.

[8] T. Nakagaki, K. Satoh, D. Ishibashi et al., "FK506 reduces abnormal prion protein through the activation of autolysosomal degradation and prolongs survival in prion-infected mice," Autophagy, vol. 9, no. 9, pp. 1386-1394, 2013.

[9] S. Z. Shah, D. Zhao, T. Hussain, and L. Yang, "Role of the AMPK pathway in promoting autophagic flux via modulating mitochondrial dynamics in neurodegenerative diseases: insight into prion diseases," Ageing research reviews, vol. 40, pp. 51-63, 2017.

[10] J. Y. Na, S. Kim, K. Song, and J. Kwon, "Rutin alleviates prion peptide-induced cell death through inhibiting apoptotic pathway activation in dopaminergic neuronal cells," Cellular and Molecular Neurobiology, vol. 34, no. 7, pp. 1071-1079, 2014.

[11] G. Forloni, R. Chiesa, O. Bugiani, M. Salmona, and F. Tagliavini, "Review: PrP 106-126-25 years after," Neuropathology and Applied Neurobiology, vol. 45, no. 5, pp. 430440, 2019.

[12] A. Corsaro, S. Thellung, V. Villa et al., "Prion protein fragment 106-126 induces a p38 MAP kinase-dependent apoptosis in SH-SY5Y neuroblastoma cells independently from the amyloid fibril formation," Annals of the New York Academy of Sciences, vol. 1010, pp. 610-622, 2003.

[13] L. Fioriti, N. Angeretti, L. Colombo et al., "Neurotoxic and gliotrophic activity of a synthetic peptide homologous to Gerstmann-Straussler-Scheinker disease amyloid protein," The Journal of neuroscience : the official journal of the Society for Neuroscience, vol. 27, no. 7, pp. 1576-1583, 2007.

[14] L. Fioriti, E. Quaglio, T. Massignan et al., "The neurotoxicity of prion protein (PrP) peptide 106-126 is independent of the expression level of $\operatorname{PrP}$ and is not mediated by abnormal $\operatorname{PrP}$ species," Molecular and Cellular Neurosciences, vol. 28, no. 1, pp. 165-176, 2005.

[15] A. Villa, A. E. Mark, G. A. Saracino et al., "Conformational polymorphism of the PrP106-126 peptide in different 
environments: a molecular dynamics study," The Journal of Physical Chemistry B, vol. 110, no. 3, pp. 1423-1428, 2006.

[16] J. H. Moon, J. H. Lee, Y. J. Lee, and S. Y. Park, “Autophagy flux induced by ginsenoside- $\mathrm{Rg} 3$ attenuates human prion proteinmediated neurotoxicity and mitochondrial dysfunction," Oncotarget, vol. 7, no. 52, p. 85697, 2016.

[17] S. Thellung, B. Scoti, A. Corsaro et al., "Pharmacological activation of autophagy favors the clearing of intracellular aggregates of misfolded prion protein peptide to prevent neuronal death," Cell death \& disease, vol. 9, no. 2, pp. 115, 2018.

[18] J. K. Jeong, Y. J. Lee, S. Y. Jeong, S. Jeong, G. W. Lee, and S. Y. Park, "Autophagic flux induced by graphene oxide has a neuroprotective effect against human prion protein fragments," International journal of nanomedicine, vol. 12, p. 8143, 2017.

[19] M. T. Islam, "Oxidative stress and mitochondrial dysfunctionlinked neurodegenerative disorders," Neurological Research, vol. 39, no. 1, pp. 73-82, 2017.

[20] J. H. Moon, J. K. Jeong, J. M. Hong, J. W. Seol, and S. Y. Park, "Inhibition of autophagy by captopril attenuates prion peptide-mediated neuronal apoptosis via AMPK activation," Molecular Neurobiology, vol. 56, no. 6, pp. 4192-4202, 2019.

[21] M. A. Smith, P. L. R. Harris, L. M. Sayre, J. S. Beckman, and G. Perry, "Widespread peroxynitrite-mediated damage in Alzheimer's disease," Journal of Neuroscience, vol. 17, no. 8, pp. 2653-2657, 1997.

[22] M. Pappolla, Y. Chyan, R. Omar et al., "Evidence of oxidative stress and in vivo neurotoxicity of beta-amyloid in a transgenic mouse model of Alzheimer's disease: a chronic oxidative paradigm for testing antioxidant therapies in vivo," The American journal of pathology, vol. 152, no. 4, p. 871, 1998.

[23] M. R. Cookson and P. Shaw, "Oxidative stress and motor neurone disease,” Brain pathology, vol. 9, no. 1, pp. 165-186, 1999.

[24] C. F. Lin, K. H. Yu, C. P. Jheng, R. Chung, and C. I. Lee, "Curcumin reduces amyloid fibrillation of prion protein and decreases reactive oxidative stress," Pathogens (Basel, Switzerland), vol. 2, no. 3, pp. 506-519, 2013.

[25] O. Milhavet, M. M. HE, W. Rachidi et al., "Prion infection impairs the cellular response to oxidative stress," Proceedings of the National Academy of Sciences of the United States of America, vol. 97, no. 25, pp. 13937-13942, 2000.

[26] N. T. Watt, M. N. Routledge, C. P. Wild, and N. M. Hooper, "Cellular prion protein protects against reactive-oxygen-species-induced DNA damage," Free Radical Biology \& Medicine, vol. 43, no. 6, pp. 959-967, 2007.

[27] C. Li, D. Wang, W. Wu et al., "DLP 1-dependent mitochondrial fragmentation and redistribution mediate prionassociated mitochondrial dysfunction and neuronal death," Aging Cell, vol. 17, no. 1, article e12693, 2018.

[28] S. Z. A. Shah, D. Zhao, T. Hussain, and L. Yang, "The role of unfolded protein response and mitogen-activated protein kinase signaling in neurodegenerative diseases with special focus on prion diseases," Frontiers in aging neuroscience, vol. 9, p. 120, 2017.

[29] E. Q. Toyama, S. Herzig, J. Courchet et al., "AMP-activated protein kinase mediates mitochondrial fission in response to energy stress," Science, vol. 351, no. 6270, pp. 275-281, 2016.

[30] E. Ferreiro, R. Costa, S. Marques, S. M. Cardoso, C. R. Oliveira, and C. M. Pereira, "Involvement of mitochondria in endoplasmic reticulum stress-induced apoptotic cell death pathway triggered by the prion peptide PrP106-126," Journal of neurochemistry, vol. 104, no. 3, pp. 766-776, 2008.

[31] E. Ferreiro, C. R. Oliveira, and C. M. Pereira, "The release of calcium from the endoplasmic reticulum induced by amyloid-beta and prion peptides activates the mitochondrial apoptotic pathway," Neurobiology of disease, vol. 30, no. 3, pp. 331-342, 2008.

[32] E. Ferreiro, R. Resende, R. Costa, C. R. Oliveira, and C. M. Pereira, "An endoplasmic-reticulum-specific apoptotic pathway is involved in prion and amyloid-beta peptides neurotoxicity," Neurobiology of disease, vol. 23, no. 3, pp. 669-678, 2006.

[33] L. Benov, L. Sztejnberg, and I. Fridovich, "Critical evaluation of the use of hydroethidine as a measure of superoxide anion radical," Free Radical Biology and Medicine, vol. 25, no. 7, pp. 826-831, 1998.

[34] J. Zielonka and B. Kalyanaraman, "Hydroethidine- and MitoSOX-derived red fluorescence is not a reliable indicator of intracellular superoxide formation: another inconvenient truth," Free Radical Biology and Medicine, vol. 48, no. 8, pp. 983-1001, 2010.

[35] S. L. Hempel, G. R. Buettner, Y. Q. O’Malley, D. A. Wessels, and D. M. Flaherty, "Dihydrofluorescein diacetate is superior for detecting intracellular oxidants: comparison with $2^{\prime}, 7^{\prime}$ dichlorodihydrofluorescein diacetate, 5 (and 6)-carboxy- $2^{\prime}$, $7^{\prime}$-dichlorodihydrofluorescein diacetate, and dihydrorhodamine 123," Free radical biology and medicine, vol. 27, no. 1-2, pp. 146-159, 1999.

[36] S. Z. A. Shah, T. Hussain, D. Zhao, and L. Yang, "A central role for calcineurin in protein misfolding neurodegenerative diseases," Cellular and molecular life sciences, vol. 74, no. 6, pp. 1061-1074, 2017.

[37] S. Z. A. Shah, D. Zhao, S. H. Khan, and L. Yang, "Regulatory mechanisms of endoplasmic reticulum resident IP3 receptors," Journal of Molecular Neuroscience, vol. 56, no. 4, pp. 938-948, 2015.

[38] S. Z. A. Shah, D. Zhao, S. H. Khan, and L. Yang, "Unfolded protein response pathways in neurodegenerative diseases," Journal of Molecular Neuroscience, vol. 57, no. 4, pp. 529$537,2015$.

[39] J. M. Hong, J. H. Moon, and S. Y. Park, "Human prion proteinmediated calcineurin activation induces neuron cell death via AMPK and autophagy pathway," The International Journal of Biochemistry \& Cell Biology, vol. 119, p. 105680, 2020.

[40] J. H. Moon and S. Y. Park, "Prion peptide-mediated calcium level alteration governs neuronal cell damage through AMPK-autophagy flux," Cell communication and signaling : CCS, vol. 18, no. 1, p. 109, 2020.

[41] M. H. Kim, H. J. Lee, S. R. Lee et al., "Peroxiredoxin 5 inhibits glutamate-induced neuronal cell death through the regulation of calcineurin-dependent mitochondrial dnamics in HT22 cells," Molecular and Cellular Biology, vol. 39, no. 20, 2019.

[42] G. M. Cereghetti, A. Stangherlin, O. Martins de Brito et al., "Dephosphorylation by calcineurin regulates translocation of Drp1 to mitochondria," Proceedings of the National Academy of Sciences of the United States of America, vol. 105, no. 41, pp. 15803-15808, 2008.

[43] F. Macian, "NFAT proteins: key regulators of T-cell development and function," Nature Reviews Immunology, vol. 5, no. 6, pp. 472-484, 2005. 
[44] F. Shibasaki, U. Hallin, and H. Uchino, "Calcineurin as a multifunctional regulator," The Journal of biochemistry, vol. 131, no. 1, pp. 1-15, 2002.

[45] I. M. Mansuy, "Calcineurin in memory and bidirectional plasticity," Biochemical and biophysical research communications, vol. 311, no. 4, pp. 1195-1208, 2003.

[46] C. N. O'Donovan, D. Tobin, and T. G. Cotter, "Prion protein fragment PrP-(106-126) induces apoptosis via mitochondrial disruption in human neuronal SH-SY5Y cells," Journal of Biological Chemistry, vol. 276, no. 47, pp. 43516-43523, 2001.

[47] L. Sinclair, V. Lewis, S. J. Collins, and C. L. Haigh, "Cytosolic caspases mediate mislocalised SOD2 depletion in an in vitro model of chronic prion infection," Disease models \& mechanisms, vol. 6, no. 4, pp. 952-963, 2013.

[48] F. Tagliavini, G. Forloni, P. D'Ursi, O. Bugiani, and M. Salmona, "Studies on peptide fragments of prion proteins," Advances in Protein Chemistry, vol. 57, pp. 171-201, 2001.

[49] A. I. Ilitchev, M. J. Giammona, C. Olivas et al., "Hetero-oligomeric amyloid assembly and mechanism: prion fragment $\operatorname{PrP}(106-126)$ catalyzes the islet amyloid polypeptide betahairpin," Journal of the American Chemical Society, vol. 140, no. 30, pp. 9685-9695, 2018.

[50] N. Singh, Y. Gu, S. Bose, S. Kalepu, R. S. Mishra, and S. Verghese, "Prion peptide 106-126 as a model for prion replication and neurotoxicity," Frontiers in bioscience : a journal and virtual library, vol. 7, pp. a60-a71, 2002.

[51] U. S. Herrmann, T. Sonati, J. Falsig et al., "Prion infections and anti-PrP antibodies trigger converging neurotoxic pathways," PLoS Pathogens, vol. 11, no. 2, article e1004662, 2015.

[52] P. Tremblay, H. L. Ball, K. Kaneko et al., "Mutant PrPSc conformers induced by a synthetic peptide and several prion strains," Journal of Virology, vol. 78, no. 4, pp. 2088-2099, 2004.

[53] C. Zhu, U. S. Herrmann, B. Li et al., "Triggering receptor expressed on myeloid cells-2 is involved in prion-induced microglial activation but does not contribute to prion pathogenesis in mouse brains," Neurobiology of Aging, vol. 36, no. 5, pp. 1994-2003, 2015.

[54] G. Giaccone and F. Moda, "PMCA applications for prion detection in peripheral tissues of patients with variant Creutzfeldt-Jakob disease," Biomolecules, vol. 10, no. 3, 2020.

[55] N. J. Haley and E. A. Hoover, "Chronic wasting disease of cervids: current knowledge and future perspectives," Annual Review of Animal Biosciences, vol. 3, pp. 305-325, 2015.

[56] A. Li, H. M. Christensen, L. R. Stewart, K. A. Roth, R. Chiesa, and D. A. Harris, "Neonatal lethality in transgenic mice expressing prion protein with a deletion of residues 105125," The EMBO Journal, vol. 26, no. 2, pp. 548-558, 2007.

[57] S. K. Kaufman and M. I. Diamond, "Prion-like propagation of protein aggregation and related therapeutic strategies," Neurotherapeutics: the journal of the American Society for Experimental NeuroTherapeutics, vol. 10, no. 3, pp. 371-382, 2013.

[58] A. Aguzzi and A. M. Calella, "Prions: protein aggregation and infectious diseases," Physiological Reviews, vol. 89, no. 4, pp. 1105-1152, 2009.

[59] J. R. Pineda, R. Pardo, D. Zala, H. Yu, S. Humbert, and F. Saudou, "Genetic and pharmacological inhibition of calcineurin corrects the BDNF transport defect in Huntington's disease," Molecular brain, vol. 2, no. 1, pp. 1-11, 2009.

[60] A. Mukherjee and C. Soto, "Role of calcineurin in neurodegeneration produced by misfolded proteins and endoplasmic reticulum stress," Current Opinion in Cell Biology, vol. 23, no. 2, pp. 223-230, 2011.

[61] P. Pinton, C. Giorgi, R. Siviero, E. Zecchini, and R. Rizzuto, "Calcium and apoptosis: ER-mitochondria Ca 2+ transfer in the control of apoptosis," Oncogene, vol. 27, no. 50, pp. 64076418, 2008.

[62] S. Klumpp and J. Krieglstein, "Serine/threonine protein phosphatases in apoptosis," Current opinion in pharmacology, vol. 2, no. 4, pp. 458-462, 2002.

[63] F. Rusnak and P. Mertz, "Calcineurin: form and function," Physiological reviews, vol. 80, no. 4, pp. 1483-1521, 2000.

[64] H. Bito, K. Deisseroth, and R. W. Tsien, "CREB phosphorylation and dephosphorylation: a Ca2+-and stimulus durationdependent switch for hippocampal gene expression," Cell, vol. 87, no. 7, pp. 1203-1214, 1996.

[65] I. A. Graef, F. Wang, F. Charron et al., "Neurotrophins and netrins require calcineurin/NFAT signaling to stimulate outgrowth of embryonic axons," Cell, vol. 113, no. 5, pp. 657670, 2003.

[66] Y.-L. Shiou, H.-T. Lin, L.-Y. Ke et al., "Very low-density lipoproteins of metabolic syndrome modulates STIM1, suppresses store-operated calcium entry, and deranges myofilament proteins in atrial myocytes," Journal of clinical medicine, vol. 8 , no. 6 , p. 881, 2019.

[67] S. Lee, J. Choi, H. Kim et al., "FK506 reduces calpain-regulated calcineurin activity in both the cytoplasm and the nucleus," Anatomy \& cell biology, vol. 47, pp. 91-100, 2014.

[68] A. Bernt, A. Y. Rangrez, M. Eden et al., "Sumoylation-independent activation of calcineurin-NFAT- signaling via SUMO2 mediates cardiomyocyte hypertrophy OPEN," Scientific Reports, vol. 6, 2016.

[69] N. Shioda and K. Fukunaga, "Functional roles of constitutively active calcineurin in delayed neuronal death after brain ischemia," Yakugaku zasshi: Journal of the Pharmaceutical Society of Japan, vol. 131, no. 1, pp. 13-20, 2011.

[70] A. M. da Cunha Pedrosa, R. Weinlich, G. P. Mognol et al., "Melatonin protects CD4+ T cells from activation-induced cell death by blocking NFAT-mediated CD95 ligand upregulation," The Journal of Immunology, vol. 184, no. 7, pp. $3487-$ 3494, 2010.

[71] N. Mukerjee, K. M. McGinnis, M. E. Gnegy, and K. K. Wang, "Caspase-mediated calcineurin activation contributes to IL-2 release during T cell activation," Biochemical and biophysical research communications, vol. 285, no. 5, pp. 1192-1199, 2001.

[72] C. M. Norris, I. Kadish, E. M. Blalock et al., "Calcineurin triggers reactive/inflammatory processes in astrocytes and is upregulated in aging and Alzheimer's models," Journal of Neuroscience, vol. 25, no. 18, pp. 4649-4658, 2005.

[73] E. Biasini, T. Massignan, L. Fioriti et al., "Analysis of the cerebellar proteome in a transgenic mouse model of inherited prion disease reveals preclinical alteration of calcineurin activity," Proteomics, vol. 6, no. 9, pp. 2823-2834, 2006.

[74] K. T. Dineley, D. Hogan, W.-R. Zhang, and G. Taglialatela, "Acute inhibition of calcineurin restores associative learning and memory in Tg2576 APP transgenic mice," Neurobiology of learning and memory, vol. 88, no. 2, pp. 217-224, 2007.

[75] S. Herzig and R. J. Shaw, "AMPK: guardian of metabolism and mitochondrial homeostasis," Nature Reviews Molecular Cell Biology, vol. 19, no. 2, pp. 121-135, 2018.

[76] X. Wei, H. Li, Y. Zhang et al., " $\mathrm{Ca}^{2+}$-calcineurin axis-controlled NFAT nuclear translocation is crucial for optimal $\mathrm{T}$ cell 
immunity in an early vertebrate," The Journal of Immunology, vol. 204, no. 3, pp. 569-585, 2020.

[77] G. P. Mognol, F. R. G. Carneiro, B. K. Robbs, D. V. Faget, and J. P. B. Viola, "Cell cycle and apoptosis regulation by NFAT transcription factors: new roles for an old player," Cell Death \& Disease, vol. 7, no. 4, pp. e2199-e2199, 2016.

[78] F. Celsi, M. Svedberg, C. Unger et al., "Beta-amyloid causes downregulation of calcineurin in neurons through induction of oxidative stress," Neurobiology of disease, vol. 26, no. 2, pp. 342-352, 2007.

[79] P. Garção, C. Oliveira, and P. Agostinho, "Comparative study of microglia activation induced by amyloid-beta and prion peptides: role in neurodegeneration," Journal of Neuroscience Research, vol. 84, pp. 182-193, 2006. 